\title{
Daily changes of the phaeoplast arrangement in the brown alga Dictyota dichotoma as studied in field experiments
}

\author{
D. Hanelt, W. Nultsch* \\ Fachbereich Biologie/Botanik der Philipps-Universität Marburg, Karl-von-Frisch-Straße, D-3550 Marburg, \\ Federal Republic of Germany
}

\begin{abstract}
Daily variations of the phaeoplast arrangements in cortical cells of Dictyota dichotoma were investigated in field experiments carried out at Helgoland (North Sea). Thallus transmittance changes caused by phaeoplast movements were used as a measure and determined with a microphotometer. The transmittance of samples exposed to daylight in the sea was measured every hour; as reference the transmittance level of the low intensity arrangement was used. In addition photomicrographs of the corresponding phaeoplast arrangement were taken. To investigate the dependence of the phaeoplast arrangement on water depth, several thalli were exposed at different depths and measured at noon. Results of earlier laboratory experiments were comparable to present results obtained in the natural habitat. According to the time of day the phaeoplasts were in the low intensity arrangement at low fluence rates and in the high intensity arrangement at high fluence rates, although the thalli were floating and, hence, continuously changed their orientation to the light direction. Down to a depth of $4 \mathrm{~m}$ the phaeoplasts moved to the high intensity arrangement at noon. At greater clepths fluence rates were too low to induce this movement. Transient changes in the fluence rate of daylight caused by cloud cover did not induce significant changes of the phaeoplast position.
\end{abstract}

\section{INTRODUCTION}

Many plants have developed the ability to change the position of their chromatophores in response to different light conditions (Senn 1908), adopting the socalled dark, low intensity, and high intensity arrangements. Although light-induced chromatophore movements have been studied by many investigators (cf. Britz 1979, Zurzycki 1980, Haupt \& Wagner 1984), our knowledge on chloroplast arrangements in plant cells in their natural habitat is relatively poor, especially in the case of marine algae.

As a quantitative measure either counting of chloroplasts with the microscope or photometric measurements of the transmittance changes caused by the chloroplast displacement have been used. Biebl (1955) measured the light transmittance of leaves of different land plants in the course of a day. He found that in some plants the changes in transmittance of the leaves

- Addressee for correspondence followed the changes in illuminance during the day, e.g. in Begonia tuberosa. In other plants, e.g. Plantago major, no transmittance changes occurred. Psaras (1986) could not observe differences in the chloroplast arrangement at midnight and in the morning in the Mediterranean subshrub Ballota.

The occurrence of the chloroplast movements and the ecological relevance of their arrangement in the course of a day is of special interest in marine algae, living in the intertidal belt, as their exposure to light varies according to position of the sun, cloud cover and tide level. The ability to displace the chromatophores is widespread only among the brown algae (Nultsch \& Pfau 1979). Especially Dictyota dichotoma has been studied in detail (for further details see Pfau et al. 1974, Nultsch et al. 1981, Pfau et al. 1988, Hanelt \& Nultsch 1989). All these experiments were done in the laboratory, i.e. with parallel light of certain fluence rates and wavelengths, impinging perpendicularly on the algae, at constant temperature and controlled hydrostatic pressure. Therefore, field experiments were indispensable. 


\section{MATERIALS AND METHODS}

Experiments were carried out at the 'Biologische Anstalt Helgoland', on the island of Helgoland, in the SE North Sea in October 1987, April 1988 and May 1989. Dictyota dichotoma (Huds.), once a typical brown alga of Helgoland, has recently been found there only occasionally. However, as all the above-cited experiments were carried out with a strain of this alga which was collected on the rocky shore of Helgoland several years ago, cultured material of this strain was exposed to natural conditions, in order to make the results comparable. It was grown in a modified Schreiber solution enriched with a vitamin solution (von Stosch \& Drebes 1964, Manton \& von Stosch 1965). A culture of young thalli was held at room temperature in a northeast-facing window and aerated continuously with a membrane pump. Broad thalli of the same age, without fertile cells and with similar pigmentation, were used. The thalli were adapted to $1000 \mathrm{~lx}$ white light, produced by a halogen lamp (Xenophot $250 \mathrm{VA}$, Osram, FRG) in a thermostated chamber at $10^{\circ} \mathrm{C}$. We used the illuminance (lx) as unit for the light measurements to make the results comparable with those of former experiments (Pfau et al. 1974). The illuminance can be converted by the relations $55 \mathrm{~lx} \simeq 1 \mu \mathrm{mol} \mathrm{m} \mathrm{m}^{-2} \mathrm{~s}^{-1} \simeq$ $0.2 \mathrm{~W} \mathrm{~m}^{-2}$, determined at Helgoland in sunlight with a LI COR photometric sensor (LI $210 \mathrm{SB}$ ), a quantum sensor (LI $190 \mathrm{SB}$ ) and a pyranometer sensor (LI $200 \mathrm{SB}$ ). The thallj were irradiated with a parallel light beam perpenaicular to their surface, which induced the low intensity arrangement of the chloroplasts (Pfau et al. 1974), which are also called phaeoplasts because of their brown colour. The low intensity arrangement is characterized by the lowest attainable light transmittance (Hanelt \& Nultsch 1989). The transmittance was

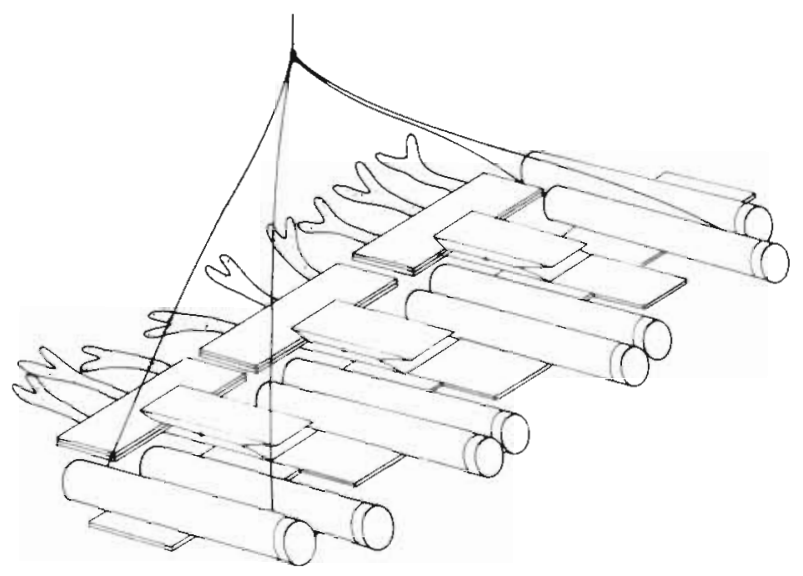

Fig. 1. Device used to submerge algae in the sea. The bases of the thalli were kept between 2 microscope slides, which were held by a clamp mounted on a board. The buoyancy of the board was adjusted by partially filling the tubes with water measured with a dual-beam microphotometer (Pfau et al. 1988). Blue light of $434 \mathrm{~nm}$ was chosen as measuring light. This wavelength is strongly absorbed by the Soret band of chlorophyll a so that transmittance changes due to even slight alterations in the phaeoplast arrangement cause a significant signal (Pfau et al. 1988). The thalli were put on a microscope slide, and the transmittance levels of defined regions of the thalli, marked on a drawing, were measured. As pigment content and, hence, thallus transmittance vary widely within one thallus (older fertile parts have a lower light transmittance than younger parts) it is necessary always to measure the same thallus regions for comparison. After exposure to field conditions, the transmittance levels of the same regions were measured again. The transmittance differences were used as a measure of phaeoplast displacement (Hanelt \& Nultsch 1989).

In the field experiments, the ends of several thalli were clamped between 2 microscope slides as shown in Fig. 1. These slides were held by 3 clamps which were mounted on an aluminum board. Polystyrol tubes were used as floats. By filling the tubes with water, the device, which was fastened to a pontoon by a line, sank to a definite water depth. Thus it was ensured that the algae floated at a constant depth independent of the tidal level. The thalli, fixed at their ends, were moved by the motion of the water. This way their floating in the natural habitat was simulated.

To measure the illuminance during the course of the day a selenium photodetector with a cosine factor was mounted on the roof of the Biologische Anstalt. The photocurrent was amplified by a current-voltage converter and fed into a recorder. Later the recorder plot was digitized with a bitpad, and the data were calculated by a personal computer. The attenuation of the daylight in different depths of the coastal water was measured with a similar waterproofed photodetector at the same place where the field experiments were carried out. All light sensors were constructed especially for field experiments and were calibrated with a LI COR photometric sensor (LI 210 SB).

In the evening before the measuring day the reference transmittance level of the low intensity arrangement was determined for each thallus. Then several thalli were mounted as clescribed and immersed in the sea at a definite water depth. The thalli were allowed to adapt to the new environment overnight. Next morning the experiment was started, and every hour one thallus was removed from the device. Immediately after removal the algae were fixed in a solution of $1 \%$ glutaraldehyde in seawater in order to prevent a change of the phaeoplast arrangement during transport to the microphotometer. The pigmentation of the thallus was not changed by using this method of fixa- 
tion. In the laboratory the thallus transmittance level was measured again.

In a second series of experiments, the dependence of the chromatophore arrangement on the water depth at the same place was measured. All thalli were removed from the device at 14:00 h summertime. They were fixed immediately and the transmittance level was determined as in the former experiments. Thalli exposed in different depths were tested on successive days to obtain a greater number of measuring values. As reference fluence rate, the average of the illuminance between 12:30 and 14:00 h was calculated and corrected for light attenuation by the waterbody, measured with the underwater detector.

In addition to the transmittance measurements, the chromatophore arrangements were determined microscopically. Photomicrographs were taken with an Zeiss IM 35 microscope and with green light (filter VG9, Zeiss, FRG). For the photographs the thalli were treated additionally with a modified Nawaschin solution (Rüffer et al. 1978), and the chromatophores were stained with $0.005 \%$ Säurefuchsin (Merck) in $1 \%$ acetic acid.

The field experiments were done in the spring because we also studied the chromatophore arrangements in other species of brown algae which occur only in this season (data not shown). In March and April the temperature of the seawater is too low to allow growth of Dictyota dichotoma (during the experiments in April 1988 about $9^{\circ} \mathrm{C}$ and in May 1989 about $11^{\circ} \mathrm{C}$ ). However, preliminary experiments carried out in October 1987, when the average water temperature was about $15^{\circ} \mathrm{C}$, showed that there are no differences in the behaviour of the phaeoplasts compared to those studied at low temperatures. Nevertheless, the algae were adapted for several days in the thermostated chamber to the water temperature of $10^{\circ} \mathrm{C}$ before they were exposed in the sea.

\section{RESULTS}

As shown by Rüfer et al. (1981), the low intensity arrangement in Dictyota dichotoma is characterized by the lowest transmittance level, the high intensity arrangement by the highest and the dark arrangement by an intermediate transmittance level. In Figs. 2 to 4 the height of each bar shows the light transmittance of one thallus resulting from the respective phaeoplast arrangement. A transmittance increase of about $50 \%$ indicates that the phaeoplasts have reached the complete high intensity arrangement. The solid line shows the daily course of the illuminance. Each dot on this line is the average of the fluence rate measured during a period of $10 \mathrm{~min}$. In the later afternoon (ca
17:00 h) the algae were shaded by the pier, whereas the photoelement on the roof was not shaded before 18:00 h. In the shaded area the fluence rate was diminished by about $75 \%$. After about 19:30 h the illuminance at both places was identical. The fluence rate measured under water depends, of course, strongly on the reflection at the surface as well as on the scattering and absorption caused by suspended particles

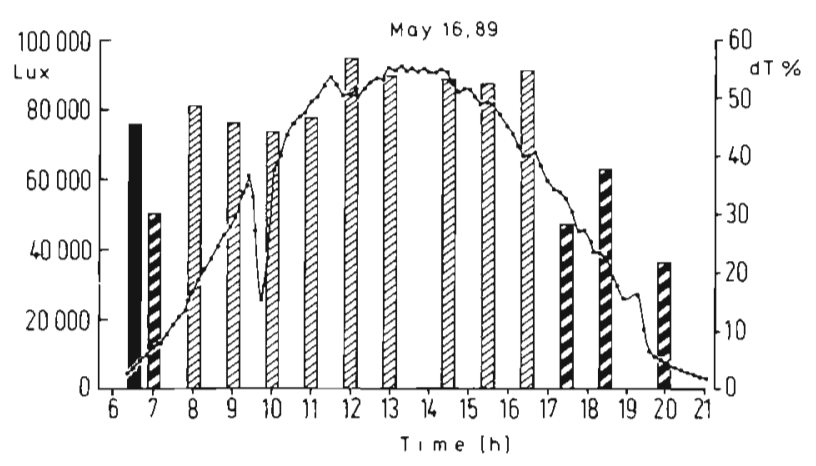

Fig. 2. Dictyota dichotoma. Daily variations of the phaeoplast arrangement of thalli, floating $10 \mathrm{~cm}$ below the water-surface. Bars show transmittance change (dT\%) relative to transmittance level of low intensity arrangement $(\mathrm{dT} \%=0)$. Each bar corresponds to the transmittance change measured of one individual thallus. Black bar represents a transmittance level indicating that the phaeoplasts are in a position caused by darkness. Heavily hatched bars represent positions between the dark- and low intensity arrangement as well as positions between the high- and low intensity arrangement. Lightly hatched bars represent a position near the strong light arrangement including the strong light arrangement itself. Solid line with dots shows the daily course of the illuminance measured on the roof of the Biologische Anstalt. Abscissa: time of day; left ordinate: illuminance in $l x_{\text {; }}$ right ordinate: transmittance change in percent, relative to the transmittance level of the low intensity arrangement $(\mathrm{dT} \%=0)$

Fig. 2 shows the daily course of the phaeoplast arrangement of thalli exposed $10 \mathrm{~cm}$ below the water surface. The illuminance in this depth was attenuated by about $17 \%$ on this day. The transmittance in Fig. 2 shows a transient decrease in the morning at 07:00 h, indicating that the phaeoplasts moved from the dark to the low intensity arrangement. With the rising sun the illuminance increased quickly so that the phaeoplasts moved to the high intensity arrangement, indicated by a transmittance increase. Until 16:30 h they stayed in this position. After this time the thalli were shaded, as mentioned above. Consequently, the phaeoplasts began to move to the low intensity arrangement again, indicated by the decreasing transmittance. The transient cloud cover between 09:30 and 10:00 h had only a slight effect on the displacement, because even the diminished fluence rate was strong enough to keep the phaeoplasts in the high 
intensity position. Moreover, the reaction was relatively slow so that it did not follow short transient changes of fluence rates.

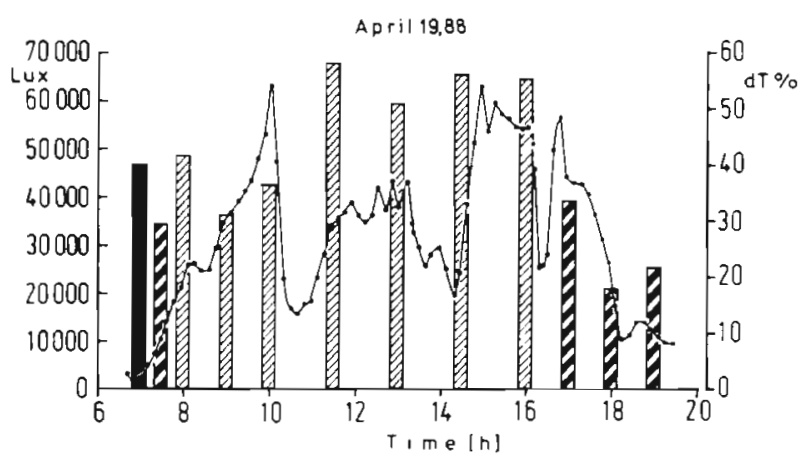

Fig. 3. Dictyota dichotoma. As Fig. 2, water depth $0.5 \mathrm{~m}$

Fig. 3 shows the results of an experiment carried out at a depth of $0.5 \mathrm{~m}$. On this day, clear and cloudy conditions alternated repeatedly. Consequently the irradiance varied considerably during the day. Only about $36 \%$ of the daylight impinging on the water surface was measured in this depth. However, irrespective of the irregular and lower overall irradiance, the phaeoplasts moved with sunrise to and stayed later in or almost in the high intensity position between 08:00 and 16:00 h.

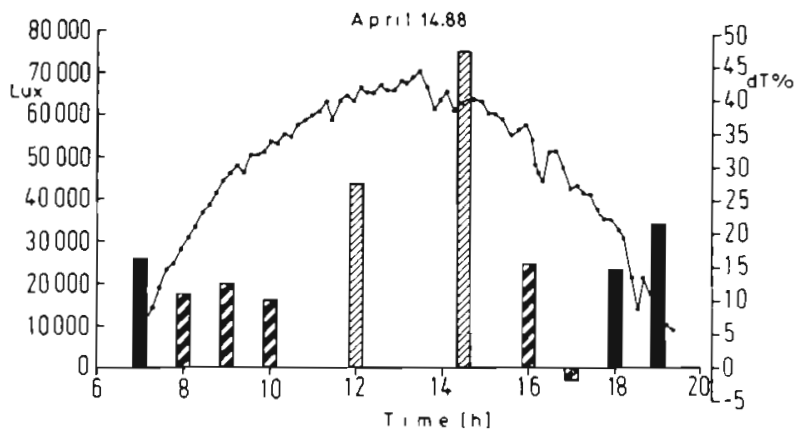

Fig. 4. Dictyota dichotoma. As Fig. 2, water depth $1 \mathrm{~m}$. At 17:00 h the phaeoplasts were in the low intensity arrangement

Fig. 4 shows the daily course of the phaeoplast arrangement at a depth of $1 \mathrm{~m}$, where only $26 \%$ of the daylight was measured. Though it was a clear day, the phaeoplast stayed in the low intensity arrangement much longer in the morning. Only at noon was the fluence rate high enough to induce the high intensity movement. The complete high intensity arrangement was reached at 14:30 h. After 16:00 h the thalli were shaded, and the phaeoplasts moved back to the low intensity arrangement. At 17:00 h the complete low intensity arrangement was achieved, and the corresponding transmittance was lower than that measured as reference before. This may be due to pigment synthesis or to the adherence of particles and microorganisms to the thallus which increases the absorbance or scatters the measuring light and, hence, diminishes the thallus transmittance. Thereafter the transmittance increased again, indicating that the phaeoplasts were moving to the dark arrangement.

As an example Fig. 5 shows some photomicrographs of the phaeoplast arrangement of thalli which floated $10 \mathrm{~cm}$ under the surface. Chromatophores, nucleus and the cytoplasma are stained by Säurefuchsin. Fig. 5a shows the high intensity arrangement at noon. The phaeoplasts are at the anticlinal cell walls. At 17:00 h (Fig. 5b) some phaeoplasts appeared at the periclinal cell walls indicating the beginning of low intensity movement. At 18:00 h the low intensity arrangement was almost reached (Fig. $5 \mathrm{c}$ ).

The chromatophore arrangements in different water depths at 14:00 h summertime are shown in Fig. 6. For this experiment 44 thalli were used. The measurements were made on successive days. The transmittance changes of thalli and the standard deviation are shown. Fluence rates measured in the respective water depth are specified above each column. The diagram shows that even at a depth of $1 \mathrm{~m}$ the phaeoplasts were in the high intensity arrangement. Between 1 and $3 \mathrm{~m}$ they occupied an intermediate position between the high and the low intensity arrangement. Finally, at $4 \mathrm{~m}$ an almost complete low intensity arrangement was reached. The fluence rate at $0.5 \mathrm{~m}$ was lower than at $1 \mathrm{~m}$, because on this day the turbidity of the water was greater and the sky was cloudier. The photomicrographs in Fig. 7 show the phaeoplast arrangements observed in thalli exposed at different depths and taken at the same time. Fig. 7 a shows cells of a thallus exposed in $1 \mathrm{~m}$ with phaeoplasts being in the high intensity arrangement, at the anticlinal cell walls. In $3 \mathrm{~m}$ (Fig. 7b) some phaeoplasts appeared at the periclinal cell walls. Fig. $7 \mathrm{C}$ shows the phaeoplast arrangement in $4 \mathrm{~m}$. The chromatophores are distributed in the low intensity arrangement.

\section{DISCUSSION}

In Dictyota dichotoma the transmittance changes measured with the microphotometer can vary considerably with the individual thallus (Pfau et al. 1988). We tried to minimize these variations by using thalli of the same age and with nearly the same pigment content. Nevertheless, they must be taken into account, if the transmittance changes measured with different thalli. during the daily course are compared. Therefore, the phaeoplast arrangements were simultaneously determined under the microscope. The arrangements 

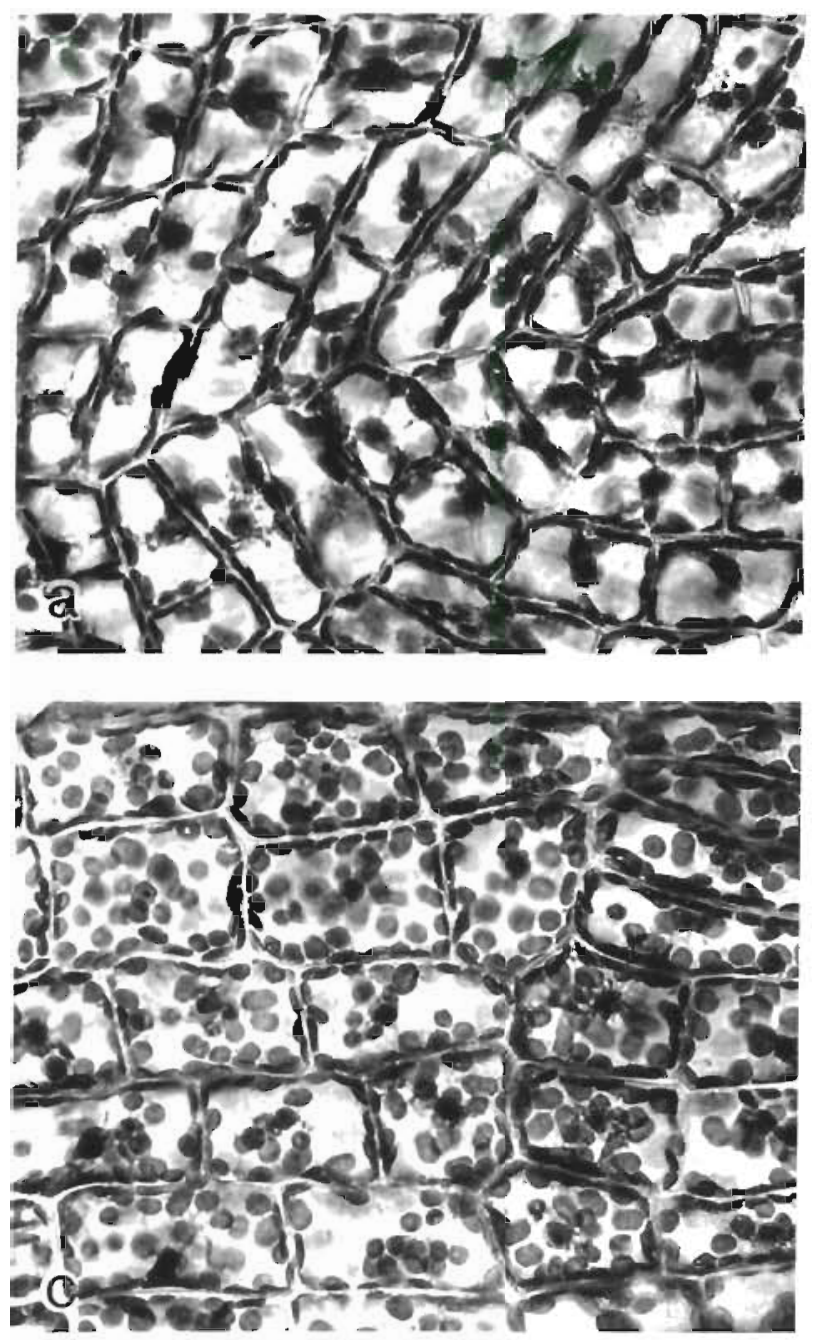

observed confirmed the results of the transmittance measurements demonstrating the reliability of both methods.

Earlier results of experiments carried out in the laboratory are comparable to those done in the natural

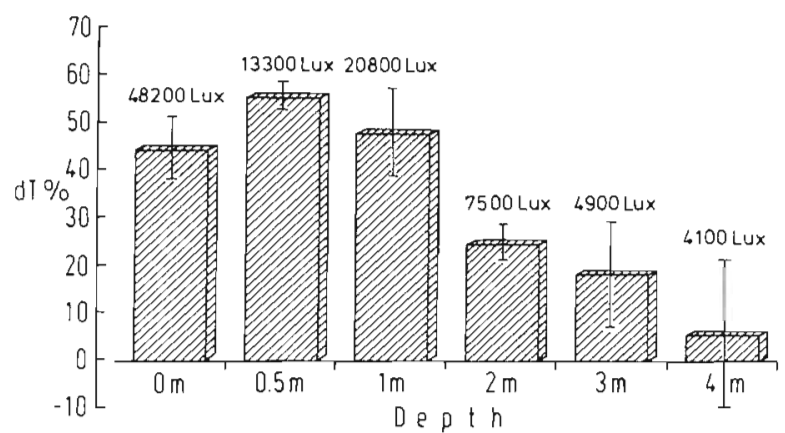

Fig. 6. Dictyota dichotoma. Transmittance changes (dT\%) relative to transmittance of low intensity arrangement (dT\% $=$ 0) of thalli, taken from different water depths at 14:00 h, measured on successive days. The corresponding illuminance is shown above the columns. Abscissa: water depth (m); ordinate: transmittance changes $(\mathrm{dT} \%)$

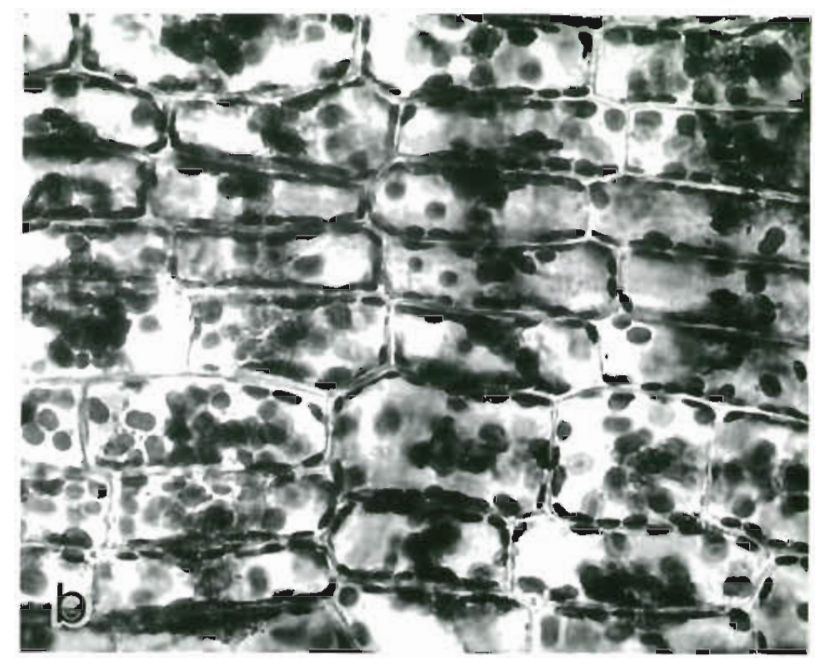

Fig. 5. Dictyota dichotoma. Photomicrographs of cortical cells of thalli, floating $10 \mathrm{~cm}$ below the water surface, taken at different times of the same day (magnification ca $550 \times$ ). Phaeoplasts stained by Säurefuchsin. (a) Phaeoplasts in high intensity arrangement at noon $(70000 \mathrm{~lx})$. (b) Phaeoplast distribution at 17:00 h $(5500 \mathrm{~lx})$. Most phaeoplasts are still at the anticlinal walls, but some have occupied the upper periclinal walls. (c) Phaeoplast distribution at 18:00 h (4000 lx). Most phaeoplasts have moved to the periclinal cell walls, so that the low intensity arrangement is almost reached. (Illuminance in brackets was measured at the respective depth at the moment of removal)

habitat, i.e. the phaeoplasts are in the high intensity arrangement at high and in the low intensity arrangement at low fluence rates (Pfau et al. 1974). This is not self-evident, as the light conditions in the laboratory are different from those in the sea. In the laboratory almost parallel light was used impinging perpendicularly on the surface of the thallus, and possible effects of scattered light could be largely neglected. In the field experiments the thalli were floating in the sea so that they are only transiently in a position perpendicular to the sunbeam. Cloudy sky and the turbidity of the water increase the amount of scattered, non-directed light. Thus, under natural conditions the phaeoplast arrangement seems to depend much more on the fluence rate than on the light direction. This is supported further by the observation that the phaeoplast arrangement corresponds to the respective irradiance at different depths, as the amount of scattered light increases with increasing depth.

The phaeoplasts of thalli floating at or near the surface are in the high intensity arrangement almost all of the day. They move to the low intensity arrangement 

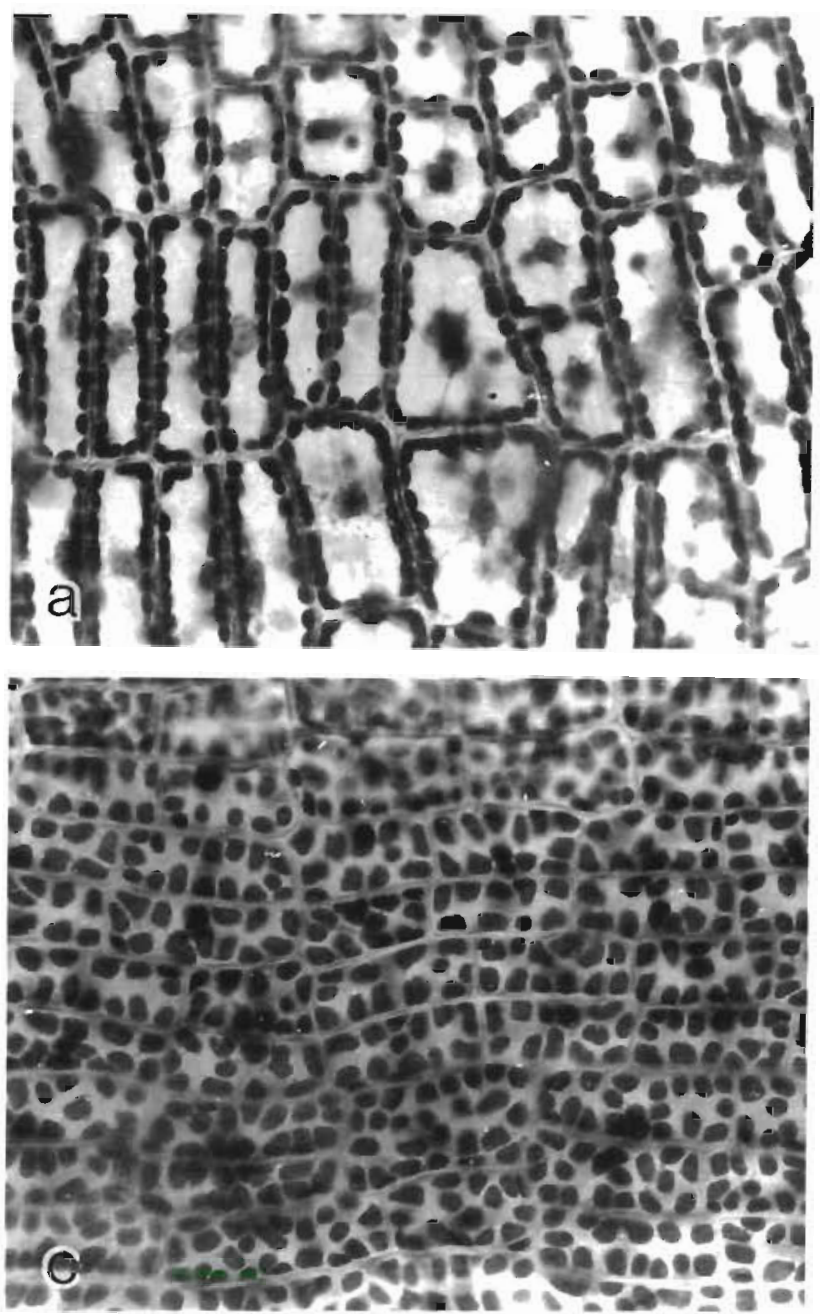

only transiently in the early morning and in the later afternoon, after and before occupying the dark arrangement. A transient cloud cover in a bright sky does not influence the arrangement, as the overall fluence rate remains mostly above the high intensity level, and the phaeoplast displacement is a relatively sluggish process which requires some hours for the complete reaction (Pfau et al. 1988). The periods during which the phaeoplasts occupy the low intensity arrangement become longer when the thalli are submerged more deeply and, hence, the overall fluence rate is lower. Thus these results support the opinion that the phaeoplast movement in Dictyota dichotoma does not regulate photosynthesis (Nultsch et al. 1981). As an adaptation to transient alterations in the fluence rate, photoinhibition and its recovery are more suitable, because they have faster kinetics and are more effective in regulating the photosynthetic activity in $D$. dichotoma (Nultsch et al. 1987). However, the high intensity movement can be regarded as a slow adaptation to the gradual increase of the fluence rate caused by decreased sea level during low tide as well as the

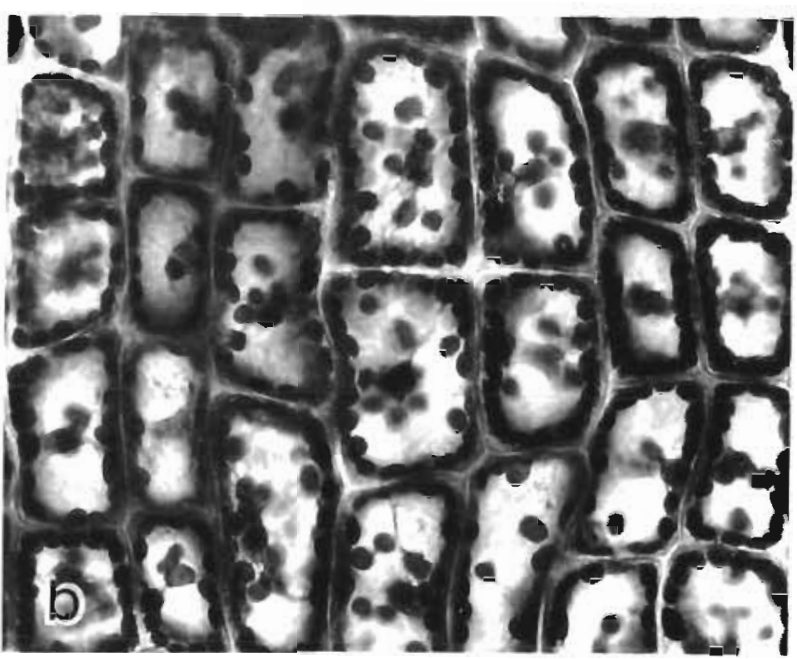

Fig. 7 Dictyota dichotoma. Photomicrographs of cortical cells of thalli taken from different water depths at 14:00 h on the same day (magnification ca $550 \times)$. (a) $1 \mathrm{~m}(12800 \mathrm{~lx})$. All phaeoplasts occupy the anticlinal cell walls (high intensity arrangement). In the middle of some cells the stained nucleus

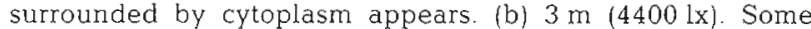
phaeoplasts have occupied the periclinal cell walls. (c) $4 \mathrm{~m}$ (2900 lx). All phaeoplasts occupy the periclinal cell walls (low intensity arrangement). (Illuminance in brackets was meas-

ured at the respective depth at the moment of removal)

diurnal course of the overall fluence rate. Hence, it might be a light protective mechanism. This question is under investigation at present.

Acknowledgements. We are indebted to the Deutsche Forschungsgemeinschaft for financial support and the staff of the Biologische Anstalt Helgoland for providing facilities for our experimental work

\section{LITERATURE CITED}

Biebl, R. (1955). Tagesgänge der Lichttransmission verschiedener Blatter Flora 142: 280-294

Britz, S. J. (1979). Chloroplast and nuclear migration. In: Haupt, W, Feinleib, M. E. (eds.) Physiology of movements. Encyclop. Plant Physiol. Vol.7 Springer, Berlin, p. $170-205$

Hanelt, D., Nultsch, W. (1989). Actionspectrum of the phaeoplast displacements from the dark - to the low intensity arrangement in the brown algae Dictyota dichotoma. J. Photochem. Photobiol, B: Biology 4: 111-121

Haupt, W., Wagner, G. (1984). Chloroplast movement. In: Colombetti, G. Lenci, F. (eds.) Membranes and sensory transduction. Plenum Press, New York, p. 331-375 
Manton, 1., von Stosch, H. A. (1965). Observations on the fine structure of male gamete of the marine centric diatom Lithodesmium undulatum. J. R. microsc. Soc. 85: $119-134$

Nultsch, W., Pfau, J. (1979). Occurrence and biological role of light-induced chromatophore displacements in seaweeds. Mar Biol. 51: 77-82

Nultsch, W., Pfau, J., Rüffer, U. (1981). Do correlations exist between chromatophore arrangement and photosynthetic activity in seaweeds? Mar. Biol. 62: 111-117

Nultsch, W., Pfau, J., Materna-Weide, M. (1987). Fluence and wavelength dependence of photoinhibition in the brown alga Dictyota dichotoma. Mar. Ecol. Prog. Ser. 41: 93-97

Pfau, J., Throm, G., Nultsch, W (1974). Recording microphotometer for determination of light induced chromatophore movements in brown algae. $Z$. Pflphysiol. 71 : $242-260$

Pfau, J., Hanelt, D., Nultsch, W. (1988). A new dual-beam microphotometer for determination of action spectra of

This article was submitted to the editor light-induced phaeoplast movements in Dictyota dichotoma. J. Plant Physiol. 133: 572-579

Rüffer, U., Nultsch, W., Pfau, J. (1978). Untersuchung zur lichtinduzierten Chromatophorenverlagerung bei Fucus vesiculosus. Helgoländer wiss. Meeresunters. 31: 333-346

Ruffer, U., Pfau, J., Nultsch, W, (1981). Movements and arrangements of Dictyota phaeoplasts in response to light and darkness. Z. Pflphysiol. 101 283-293

Psaras, G. K. (1986). Chloroplast arrangement along intercellular spaces in the leaves of a Mediterranean subshrub. J. Plant Physiol. 126: 189-193

Senn, G. (1908). Die Gestalts- und Lageveränderung der Pflanzen-Chromatophoren. Engelmann Verlag, Leipzig

von Stosch, H. A., Drebes, G. (1964). Entwicklungsgeschichtliche Untersuchungen an zentrischen Diatomeen IV Helgoländer wiss. Meeresunters. 11. 209-257

Zurzycki, J. (1980). Blue light-induced intracellular movements. In: Senger, H. (ed.) The blue light syndrome. Springer, Berlin, p. 50-68

Manuscript first received: October 10,1989

Revised version accepted: January 9, 1990 